\title{
Fluctuations in anti-nRNP levels in patients with mixed connective tissue disease are related to disease activity as part of a polyclonal B cell response
}

\author{
P M HOUTMAN,${ }^{1}$ C G M KALLENBERG ${ }^{2}$ P C LIMBURG ${ }^{2}$ \\ M A VAN LEEUWEN, ${ }^{1}$ M H VAN RIJSWIJK, ${ }^{1}$ AND T H THE
}

From the Departments of ${ }^{1}$ Rheumatology and ${ }^{2}$ Clinical Immunology, University Hospital, Groningen, The Netherlands

SUMMARY In a follow up study of 11 patients with mixed connective tissue disease the levels of $\vec{\circ}$ antibodies to nuclear ribonucleoprotein (nRNP) as measured by an enzyme linked immunosor- ${ }^{\infty}$ bent assay (ELISA) were related to clinical activity of disease. To assess the relation between anti-nRNP levels and disease activity the levels of total immunoglobulin G, IgM rheumatoid ${ }^{\circ}$ factor (IgM RF), and antibodies to an unrelated antigen (tetanus toxoid) were determined $\vec{O}$ simultaneously. No significant changes in anti-nRNP levels were noted in four patients with minor $\stackrel{\odot}{0}$ activity of disease. Major flares of disease were observed in seven patients. Clinical symptoms were preceded by a rise in anti-nRNP level in these patients unless they received immunosuppressive agents before the exacerbation. Conversely, when a rise in anti-nRNP level occurred a majogro flare of disease was followed in all but one case. Anti-nRNP levels fell during clinical improvement whether or not immunosuppressive treatment was given. All patients showe parallel fluctuations in anti-nRNP, IgM RF, and total immunoglobulin G levels. Furthermore, parallel fluctuations were seen in the levels of anti-nRNP and antibodies to tetanus toxoid except in one patient. We conclude that measurement of anti-nRNP by ELISA may be a guide forס disease activity in connective tissue disease. Fluctuations of anti-nRNP are not restricted to this $\stackrel{\varrho}{\Rightarrow}$ antibody, however, but are part of a more polyclonal activity of the B lymphocyte system.

Mixed connective tissue disease (MCTD) ${ }^{1}$ is serologically characterised by the presence of antibodies to nuclear ribonucleoprotein (nRNP). The clinical syndrome is an overlap of systemic lupus erythematosus (SLE), scleroderma, polymyositis, and rheumatoid arthritis. The significance of antibodies to nRNP (anti-nRNP) as marker antibodies for a distinct disease entity has been controversial. ${ }^{2} \mathrm{Re}$ cent observations have attracted new interest for anti-nRNP as a possibly pathogenic factor in connective tissue disease. Nuclear deposits of immunoglobulins in epidermal and dermal cells have been considered as a real in vivo phenomenon in patients with anti-nRNP antibodies. ${ }^{3}$ In vitro studies have shown that living cells may be penetrated by anti-nRNP either by way of cell membrane Fc

Accepted for publication 17 April 1986.

Correspondence to Dr C G M Kallenberg, Department of Clinical Immunology, University Hospital, Oostersingel 59, 9713 EZ Groningen, The Netherlands. receptors ${ }^{4}$ or through increased permeability of cell membranes. ${ }^{5}$ The antigen belongs to the so-called $\overline{0}$ small nuclear RNPs (snRNP). These proteins are $\frac{3}{3}$ involved in the mechanism of splicing of messenger RNA precursors in the cell nucleus. ${ }^{6}$ As such, anti-을 nRNP might influence protein synthesis at the cellular level. Besides biochemical studies on struc-음 ture, organisation, and function of snRNPs, clinical $\$$ studies on the relation between serum levels of antinRNP and disease manifestations may help to $N$ elucidate the pathogenic role of anti-nRNP. Unlike antibodies to double stranded DNA (antidsDNA) ${ }^{7} 8$ anti-nRNP has not been studied exten- $\omega$ sively in relation to disease activity in long term follow up studies. In addition, measurement ofo serum levels of anti-nRNP as described in previous studies has been performed by titration techniques ${ }^{+}$ with unpurified antigens, such as the immuno- -0 fluorescence, immunodiffusion, and haemagglutina- $-\frac{\text { Dे }}{D}$ tion techniques. ${ }^{9}$ 


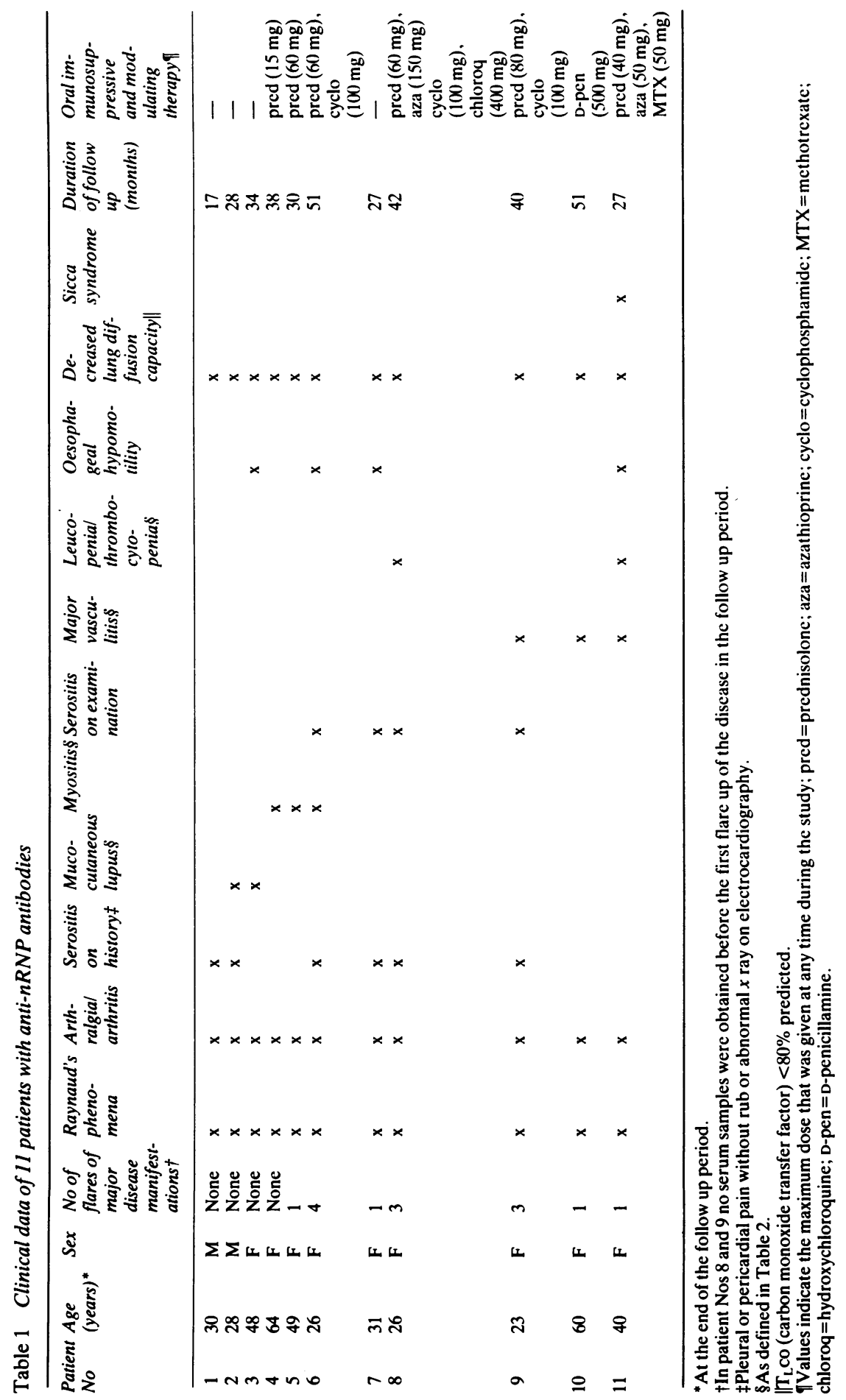


In a previous report we described an enzyme linked immunosorbent assay (ELISA) for measurement of anti-nRNP. ${ }^{10}$ We showed that the ELISA is as sensitive as counterimmunoelectrophoresis in the detection of anti-nRNP.

In the present study we have evaluated the measurement of anti-nRNP by ELISA as a guide for disease activity in patients with mixed connective tissue disease. To delineate the specific relation between fluctuations in anti-nRNP levels and disease activity we determined simultaneously levels of antibodies to an unrelated antigen (tetanus toxoid), and levels of IgM rheumatoid factor, another autoantibody frequently present in the sera of these patients. Since autoantibodies in connective tissue disease belong predominantly to the immunoglobulin $\mathrm{G}$ (IgG) class ${ }^{11}$ we also measured total IgG in all serum samples. The results of our study show that major flares of disease are accompanied by fluctuations in anti-nRNP. These fluctuations are, however, not specific for anti-nRNP.

\section{Patients and methods}

PATIENTS AND SERA

Serum samples containing antibodies to nRNP-as determined by counterimmunoelectrophoresis (CIE) - were taken from 11 patients. Clinical data of the patients are presented in Table 1 . The mean period of follow up of the patients was 35 months (range 17-51 months). Seven patients were treated with immunosuppressive therapy (corticosteroids, azathioprine, cyclophosphamide, or methotrexate (MTX)) at some time during the study period. Patients were seen at regular intervals at the outpatient department during periods of relatively stable disease activity and were admitted to the hospital during flares of major disease activity. Serum samples were drawn at each visit to the outpatient department and every two weeks during admission. All sera were also tested for antibodies to double stranded (ds) DNA by the indirect immunofluorescence technique on Crithidia luciliae, and for antibodies to other extractable nuclear antigens (anti-Sm, anti-SSB, and anti-SSA) as detected by counterimmunoelectrophoresis (CIE). Only one patient (No 11) showed a positive test for anti-dsDNA at the time of her major exacerbation. Anti-Sm was detected in the sera of patient No 7, anti-SSB in the sera of patient No 4, and anti-SSA in the sera of patients Nos 4 and 9 . The interval between the samples never exceeded three months unless the patient had stable disease activity throughout the entire follow up period. At the time of serum sampling clinical disease activity was scored according to Becker et al, ${ }^{12}$ with some minor modifications (Table 2). A patient was considered to have stable disease activity when major manifestations did not occur during the follow up period. Major disease manifestations were defined as the presence of severe proliferative glomerulonephritis, severe haemolytic anaemia $(\mathrm{Hb}<5 \mathrm{~g} \%(50 \mathrm{~g} / \mathrm{l}))$ or thrombocytopenia $\left(<50000 / \mathrm{mm}^{3} \quad\left(50 \times 10^{9} / 1\right)\right)$, severe CNS involvement (convulsions, coma, transverse myelitis), serositis on examination (persistent pleural or pericardial rub, abnormal $x$ ray, or ECG), myositis, or major vasculitis. Manifestations of disease that could be attributed on clinical grounds to causes other than connective tissue disease, such as infections, untoward reactions to drugs, etc, were excluded from the analysis. None of the patients was immunised with tetanus toxoid during a period of three years before or during the study period.

MEASUREMENT OF ANTI-nRNP

Serum levels of anti-nRNP were determined in an ELISA system as described previously. ${ }^{10}$ Briefly, the nRNP antigen was prepared from rabbit thymus acetone powder (Pel Freez, Arkansas) by fractionated ammonium sulphate precipitation and affinity chromatography. In order to prevent proteolytico degradation of the antigens all buffers contained protease inhibitors. The eluate was extensivelyo dialysed and coated onto microtitre wells. The optimum protein concentration in the antigen solution appeared to be $1.5 \mu \mathrm{g} / \mathrm{ml}$ or $0.15 \mu \mathrm{g} /$ well. Anti-nRNP concentrations were expressed in relative units/ml at a 1:100 dilution. The concentration in our reference serum was arbitrarily fixed at 100 units. This reference serum was used for measurement of anti-nRNP in all sera, except for those of patient No 11. The slopes of the dilution curves of the sera of this patient were not parallel to the slopes of the curves for other sera, including the reference serum, but were parallel to each other. Therefore a pool of all serum samples of this patient was used as a reference-also arbitrarily fixed at 100 -in her longitudinal study. Positive results in ELISA were obtained only in sera with anti-nRNP or anti-Sm specificity, or both, as determined by CIE. Sera with antinuclear antibodies of specificities other than anti-nRNP or anti-Sm yielded values less than 1.5 units, which is comparable with the results obtained in healthy controls.

Testing of positive sera in different ELISA plates and on different days yielded an interassay variation of less than $10 \%$.

A significant change in the level of anti-nRNP was arbitrarily considered present when the level of anti-nRNP increased or decreased 1.5 times compared with the previous sample. 
Table 2 Disease activity index in patients with anti-nRNP antibodies*

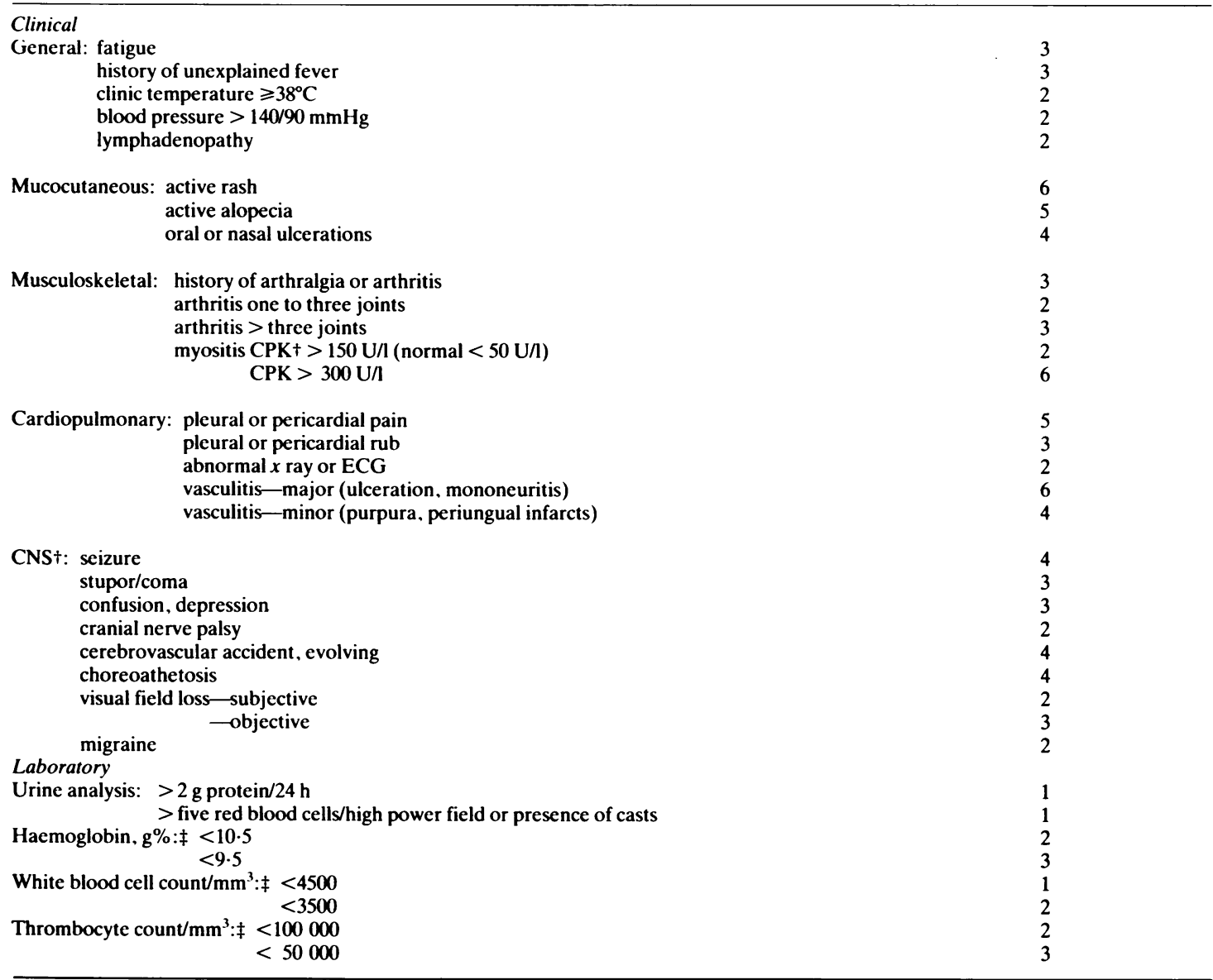

${ }^{*}$ According to Becker $e$ e al $^{12}$ with minor modifications.

$+\mathrm{CPK}=$ creatine phosphokinase $; \mathrm{CNS}=$ central nervous system.

$\ddagger$ SI conversion: haemoglobin, $\mathrm{g} \% \times 10=\mathrm{g} / \mathrm{l}$; white blood cell count $/ \mathrm{mm}^{3} \times 10^{6}=$ cells $/ 1$; thrombocyte count $/ \mathrm{mm}^{3} \times 10^{6}=$ cells $/ 1$.

MEASUREMENT OF ANTIBODIES TO TETANUS TOXOID AND IgM RHEUMATOID FACTOR

Serum levels of antibodies to tetanus toxoid and IgM rheumatoid factor (IgM RF) were assessed by an ELISA with essentially the same method as used for the measurement of anti-nRNP levels.

For the determination of antitetanus antibodies $150 \mu$ l tetanus toxoid (RIV, Bilthoven, The Netherlands, code VGT No 23) at a concentration of one Limes flocculationis/ml was coated onto microtitre plates (Titertek). For the determination of IgM RF $100 \mu \mathrm{l}$ heat aggregated IgG $\left(30 \mathrm{~min}, 56^{\circ} \mathrm{C}\right)$ at a concentration of $40 \mu \mathrm{g} / \mathrm{ml}$ was coated per microtitre well. Sera were diluted at least $1: 100$ in Tweenbovine serum albumin buffer and incubated for 45 $\min$ at $37^{\circ} \mathrm{C}$ in both ELISA systems. Diluted (1:4000) antihuman IgG conjugated to horseradish peroxidase (HRP) (Kallestadt) was used as conjugate in the antitetanus ELISA and 1:500 diluted goat $F(a b)_{2}$ antihuman IgM conjugated to HRP (Cappel) as conjugate in the IgM RF ELISA. The antitetanus and IgM RF concentrations were expressed as units and international units $/ \mathrm{ml}$ using the standard curve of a positive antitetanus reference pool and rheumatoid factor reference serum (Behring, Diagnostika), respectively. 


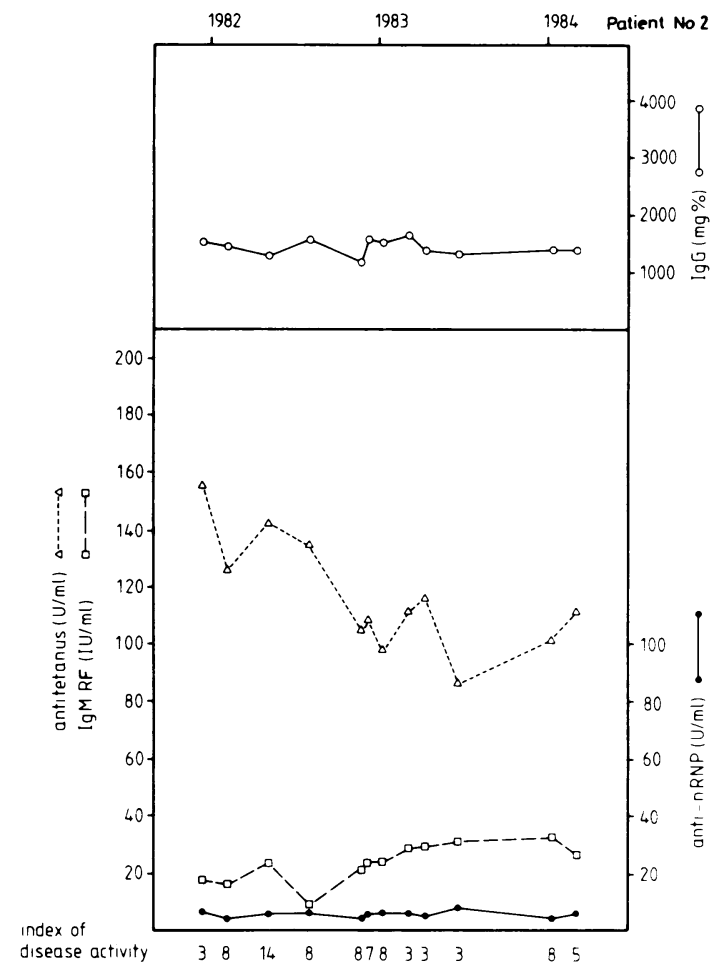

Fig. 1 Patient No 2, male, born in 1956, had stable disease activity during the follow up period. He complained of Ravnaud's phenomenon, intermittent arthralgia, and chest pain suggestive of pleurisy which could not be substantiated. A butterfly rash developed in May 1982. He was never admitted to the hospital because of a major flare up of his disease. Anti-nRNP levels were constant at a low level during the entire period. SI conversion. $\operatorname{Ig} G m g \% \times I 0=m g / l$.

All serum samples from one patient were assayed simultaneously for anti-nRNP, antitetanus antibodies, and IgM RF by ELISA.

\section{MEASUREMENT OF IMMUNOGLOBULIN G} ( IgG)

Serum levels of IgG were determined by nephelometry.

\section{S T A T IS T I C S}

The inter-relationship between changes in antinRNP and antitetanus, IgM RF, total IgG, and index of disease activity respectively were calculated by Kendall rank order coefficients (Kendall's tau) ${ }^{13}$ and tested for significance with Student's $t$ test (degrees of freedom $=n-2$ ). Fluctuations of antinRNP were only considered in relation to IgM RF when the sera of the patient were positive for IgM RF (yielding values above $40 \mathrm{IU} / \mathrm{ml}$ ).

\section{Results}

FLUCTUATIONS OF ANTI-nRNP LEVELS IN

RELATION TO DISEASE ACTIVITY

Four patients (Nos 1-4) did not suffer from major flares of disease during the entire period of the follow up study (Table 1). In these patients there was no significant change in the levels of anti-nRNP or the index of disease activity as assessed by Kendall's analysis. An example of antibody profiles in patient No 2 with stable disease activity is given in Fig. 1.

Fourteen major flares of disease occurred in seven patients (Nos 5-11. Table 1) during the follow up period. In two cases (Nos 8 and 10) a flare of disease was already present at the beginning of the follow up. Thus changes in anti-nRNP levels preceding the disease manifestations could be studied in relation to 12 flares (Table 3). In three cases (Nos 5, 7 (Fig. 2) and 11 (Fig. 4)) no immunosuppressive therapy was given in the period before the first exacerbation A rise of anti-nRNP preceded the major diseased manifestations in these patients. Nine episodes of major disease activity developed in three patient (Nos 6 (Fig. 3), 8, and 9) on immunosuppressive therapy. Four episodes, all serositis, were not preceded by a rise in anti-nRNP levels. In five episodes anti-nRNP levels rose before the exacerbation. These data are summarised in Table 3 .

Six out of the seven patients with major disease manifestations were treated with immunosuppressive agents (Table 1, Figs 2-4) during the follow up period. In all these patients a decrease in anti-nRNP levels was observed associated with clinical recovery. In one patient (No 5) clinical improvement and concomittant decrease of anti-nRNP levels occurred before institution of immunosuppressive agents.

We related fluctuations in anti-nRNP levels to changes in disease activity as determined by a scoring system based on the diversity and the severity of the clinical symptoms. In five out of the seven patients with major flares of disease a significant correlation was found between antinRNP levels and index of disease activity during the follow up period (Table 4).

\section{PREDICTIVE VALUE OF A RISE OF}

A NTI-nRN P LEVELS

A rise of the anti-nRNP level was seen 10 times in the group of 11 patients. In nine out of these 10 cases this rise was followed by a major flare of disease. In most cases anti-nRNP levels rose in- 
Table 3 Episodes of major disease activity in relation to anti-nRNP profiles in patients with anti-nRNP

\begin{tabular}{llll}
\hline $\begin{array}{l}\text { Major disease } \\
\text { manifestation* }\end{array}$ & $\begin{array}{l}\text { Patient Immunosuppressive } \\
\text { No }\end{array}$ & $\begin{array}{l}\text { Rise of anti-nRNP+ } \\
\text { therapy at the time } \\
\text { of flare up }\end{array}$ \\
\hline Severe serositis & 6 & + & flare of disease \\
& 6 & + & - \\
& 7 & - & + \\
& 8 & + & + \\
& 8 & + & - \\
Myositis & 9 & + & - \\
& 5 & - & + \\
Vasculitis & 6 & + & + \\
& 6 & + & + \\
& 9 & + & + \\
& 9 & + & +
\end{tabular}

*As defined in 'Patients and methods'.

†A rise of anti-nRNP was considered present when anti-nRNP rose at least $1 \cdot 5$-fold.

sidiously. In patient No 7 (Fig. 2) these levels even rose gradually up to 12 months before the outbreak of the major manifestations.

\section{SPECIFICITY OF THE FLUCTUATIONS IN}

ANTI-nRN P LEVELS

Rank order correlations were calculated to determine whether fluctuations in the levels of anti-nRNP were related to fluctuations in the levels of antibodies of other specificities. Another autoantibody (IgM RF), an antibody to an unrelated antigen (tetanus toxoid), and total IgG levels were studied. In two out of the four patients with stable disease activity a significant correlation was found between fluctuations in anti-nRNP and antitetanus antibodies. Anti-nRNP levels correlated with the levels of total IgG in one of them. In six out of seven patients with major manifestations of disease a significant correlation was found between the fluctuations in anti-nRNP levels and the fluctuations in the levels of IgM RF, antibodies to tetanus toxoid, and total IgG (Table 4). The remaining patient, No 7 , showed a parallel rise of anti-nRNP and total IgG levels without any change in the level of antitetanus antibody, whereas IgM RF was persistently negative (Fig. 2). Results are summarised in Table 4.

\section{Discussion}

Accurate measurement of antibodies and definition of disease activity are a prerequisite for longitudinal studies of the relation between antibody levels and disease manifestations. The ELISA for measurement of anti-nRNP antibodies used in this study has

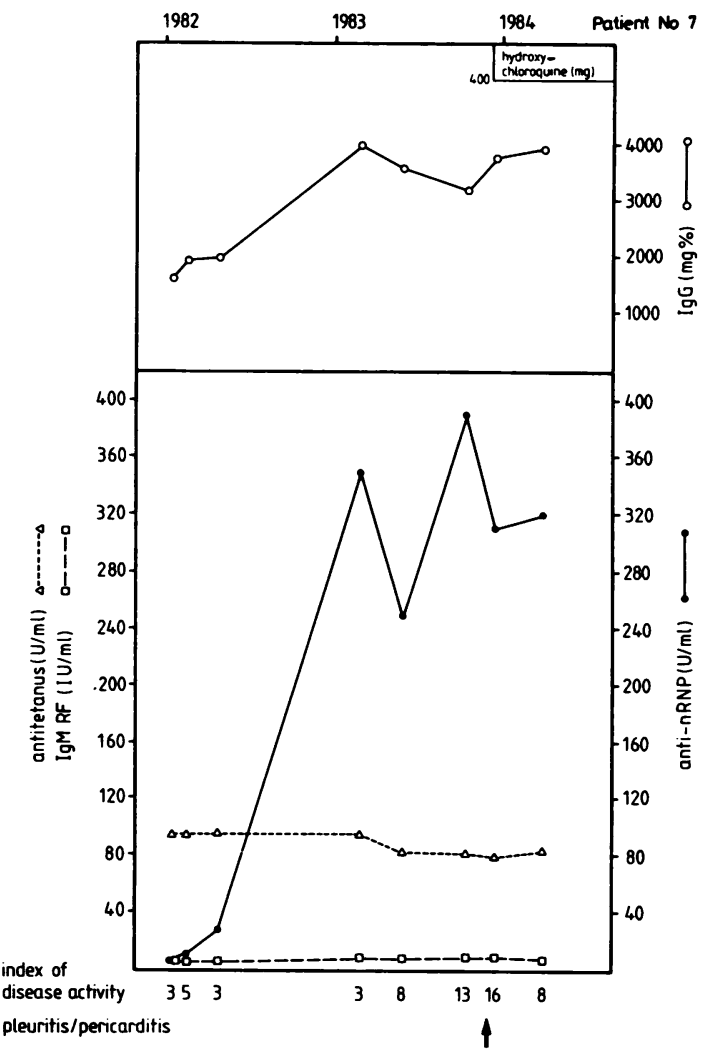

Fig. 2 Patient No 7, female, born in 1953, developed arthralgia and Raynaud's phenomenon in 1982. In 1983 arthritis of the hands and elbows developed, and oesophageal hypomotility was found. Treatment with hydroxychloroquine was instituted. She then started to complain of pleuritic pains, increasing in severity. In November 1983 a diagnosis of pleuropericarditis was made. $A$ continuous rise in the levels of anti-nRNP and $\operatorname{IgG}$ was seen during the follow up period starting from the very onset of her disease. SI conversion: $I g G m g \% \times 10=m g / l$.

proved to be antigen specific and to allow the detection of fluctuations in anti-nRNP levels in relation to disease manifestations. ${ }^{10}$ Definition of disease activity in connective tissue disease is hampered by the diversity of the disease manifestations. Assessment of disease activity may be approached in two ways: firstly, by assessing the severity of each manifestation separately and secondly, by summing the number of manifestations of clinical disease. For the latter approach we have applied the index of disease activity for SLE of Becker $e t$ al. ${ }^{12} \mathrm{We}$ introduced some slight modifications, adding myositis as an important symptom in MCTD and omitting results of antinuclear antibody 


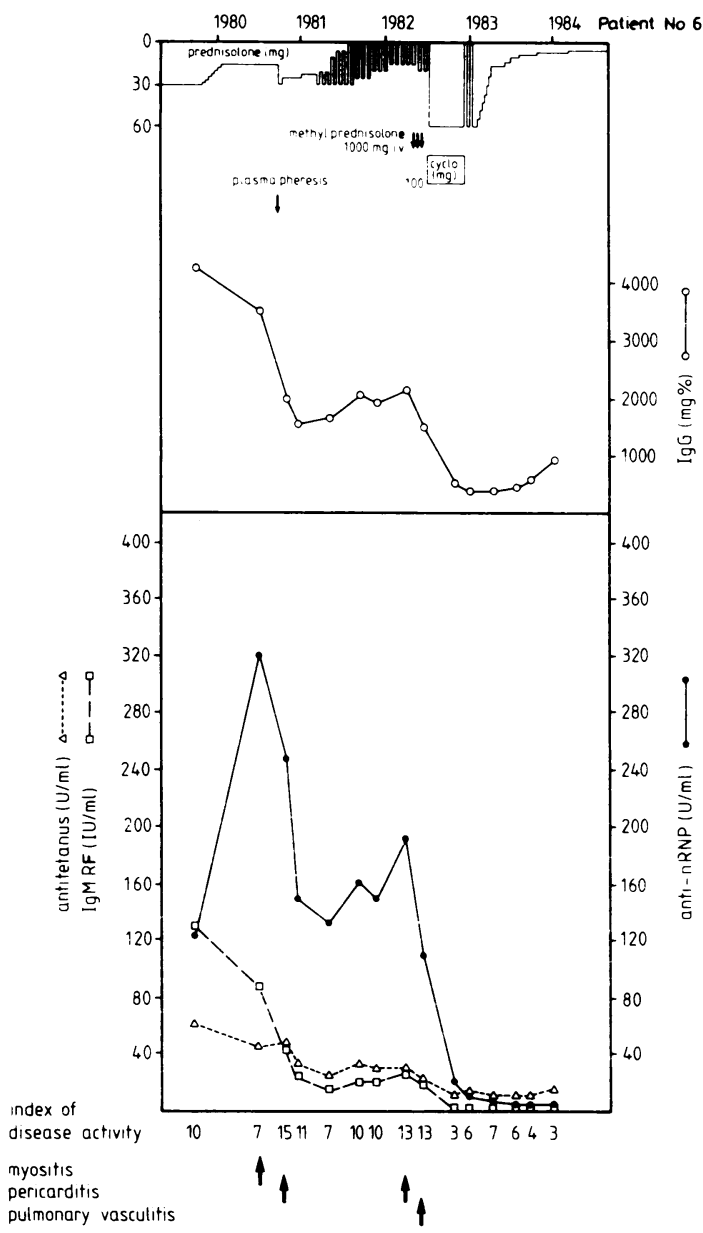

Fig. 3 Patient No 6, female, born in 1958, was admitted to the hospital in October 1979 because of loss of weight, muscle weakness, and arthralgia. The first rise in the level of anti-nRNP coincides with an increase in creatinine phosphokinase (CPK) values compatible with the development of myositis. Despite therapy with prednisolone (17.5 mg/day) symptoms worsened. Plasmapheresis was performed while prednisolone dosage was kept constant. Clinical symptoms improved and CPK values returned to normal. She was readmitted to the hospital because of fever and pericarditis in October 1980. At that time the level of anti-nRNP was still decreasing. The dosage of prednisolone was increased to $30 \mathrm{mg} /$ day and symptoms subsided. A second rise in the level of anti-nRNP coincided with a major exacerbation of her disease in June 1982 manifesting as pericarditis and severe pulmonary hypertension with right sided cardiac failure probably due to pulmonary vasculitis. Therapy was started in July 1982 with methylprednisolone (1000 mg/week intravenously) and cyclophosphamide (100 mg/day orally). Symptoms subsided and the patient was able to resume her daily work. The anti-nRNP level decreased and kept in the lower range on therapy with $7 \mathrm{mg}$ of prednisolone daily during 1984. SI conversion: $\lg G$ $m g \% \times 10=m g / l$.

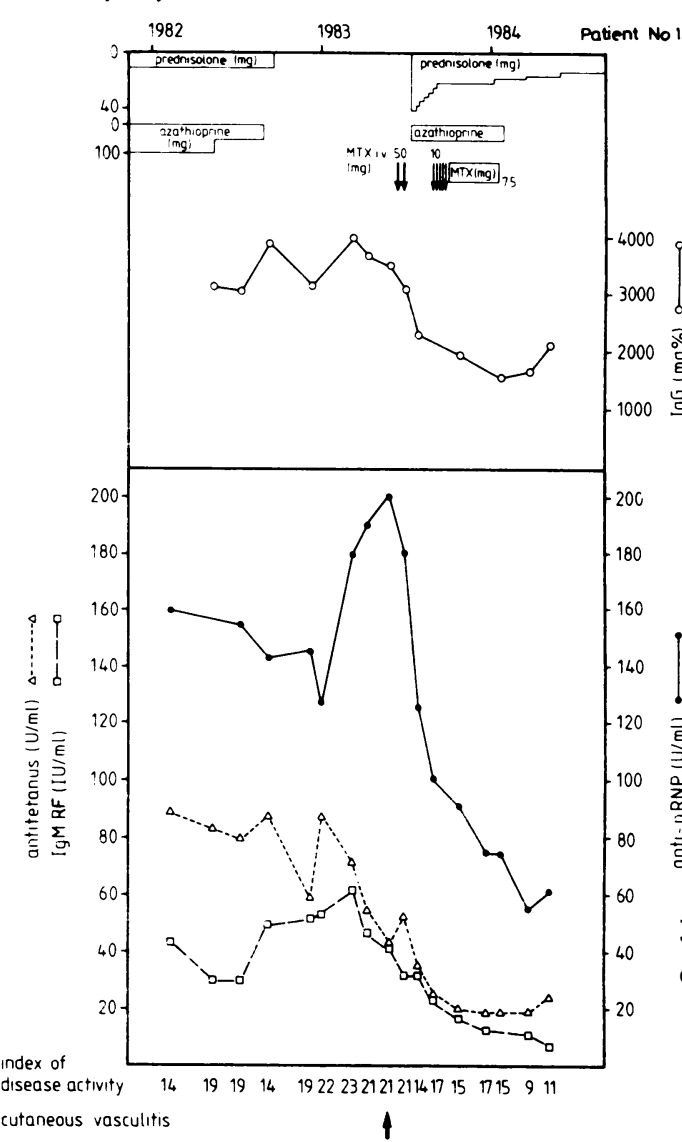

Fig. 4 Patient No 11, female, born in 1944, was referred in 1983 because of severe ulceration on the lower legs due to vasculitis. She had a long history of Raynaud's phenomenon, pleuritic chest pain, febrile periods, leucopenia, arthralgia, and sicca syndrome. A rise in anti-nRNP levels preceded the flare of vasculitis. Anti-nRNP levels decreased with treatment and resolution of the ulcers. SI conversion: $I g G \mathrm{mg} \% \times 10=m \mathrm{~g} / \mathrm{l}$.

tests and levels of complement component $\mathrm{C} 3$, as these immunological parameters are probably related to the levels of anti-nRNP antibody. When the manifestations of disease most commonly encountered are included and arbitrary points assigned to each manifestation the index combines both of the above approaches. It does not discriminate, however, between one single manifestation of major activity and several manifestations of minor activity. For this reason disease activity was not only approached by the defined index of disease activity but also by the occurrence of major manifestations (myositis, serositis, and vasculitis in our group of patients). 
Table 4 Kendall rank order correlation coefficients between levels of anti-nRNP and levels of antitetanus antibodies, $\operatorname{Ig} M R F$, total $\operatorname{Ig} G$, and the index of disease activity

\begin{tabular}{|c|c|c|c|c|c|c|}
\hline \multirow{2}{*}{$\begin{array}{l}\text { Patient } \\
\text { No }\end{array}$} & \multirow{2}{*}{$\begin{array}{l}\text { Number of } \\
\text { serum samples }\end{array}$} & \multicolumn{4}{|c|}{ Fluctuations of anti-nRNP in relation to: } & \multirow{2}{*}{$\begin{array}{l}\text { Representation } \\
\text { in figure }\end{array}$} \\
\hline & & $\begin{array}{l}\text { Antitetanus } \\
\text { antibodies }\end{array}$ & $I g M R F$ & $\operatorname{Ig} G$ & $\begin{array}{l}\text { Index of } \\
\text { disease } \\
\text { activity }\end{array}$ & \\
\hline 1 & 5 & 0 & $\dagger$ & & $\ddagger$ & \\
\hline 2 & 13 & $0 \cdot 38^{*}$ & + & $0 \cdot 13$ & $\ddagger$ & 1 \\
\hline 3 & 7 & $0.71^{*}$ & 0.41 & 0.33 & $\ddagger$ & \\
\hline 4 & 10 & $0 \cdot 10$ & $0 \cdot 30$ & $0 \cdot 17$ & $\ddagger$ & \\
\hline 5 & 15 & $0 \cdot 66^{* * *}$ & $0 \cdot 73^{* * *}$ & $0.77^{* * *}$ & $0 \cdot 72^{* * *}$ & \\
\hline 6 & 15 & $0 \cdot 66^{* * *}$ & $0 \cdot 69^{* * *}$ & $0 \cdot 59^{* *}$ & $0 \cdot 57^{* *}$ & 3 \\
\hline 7 & 8 & $-0 \cdot 37$ & + & $0.71^{* *}$ & 0.39 & 2 \\
\hline 8 & 25 & $0 \cdot 64^{* * *}$ & + & $0.54 * * *$ & $0 \cdot 27^{*}$ & \\
\hline 9 & 24 & $0 \cdot 20$ & $0 \cdot 61^{* * *}$ & $0.52^{* * *}$ & $0 \cdot 15$ & \\
\hline 10 & 9 & $0 \cdot 61^{*}$ & $0.49^{*}$ & $0 \cdot 63^{*}$ & $0.61^{*}$ & \\
\hline 11 & 16 & $0.45^{* *}$ & $0.54^{* *}$ & $0 \cdot 61^{* *}$ & $0 \cdot 50^{* *}$ & 4 \\
\hline
\end{tabular}

${ }^{*} \mathrm{p}<0.05 ;{ }^{* *} \mathrm{p}<0.01 ;{ }^{* * *} \mathrm{p}<0.001$.

†IgM RF negative sera (yielding less than $40 \mathrm{IU} / \mathrm{ml}$ ).

$\$$ No major flares of disease during the study period.

In four patients without major disease manifestations no significant changes in anti-nRNP levels were seen. On the contrary, in seven patients with major flares of disease significant fluctuations of these levels were observed. Since immunological processes probably precede the clinical manifestations of disease we studied changes in the autoantibody level just before the exacerbation. Eight out of 12 major flare ups were preceded by a rise of the anti-nRNP level; in five cases despite the use of immunosuppressive therapy. The four episodes of serositis not preceded by a rise of anti-nRNP occurred while the patients were taking immunosuppressive agents. These data suggest a relation between anti-nRNP levels and disease activity but do not support a direct pathophysiological role for anti-nRNP antibodies. Conversely, a rise of antinRNP appears to predict a major disease manifestation irrespective of the use and dosage of immunosuppressive agents: a major flare was observed after nine out of 10 periods of rising anti-nRNP levels. It is noteworthy that the rise of the anti-nRNP level was usually very gradual and lasted for six to 12 months before the flare was apparent. The possibility that early institution of immunosuppressive agents may prevent the development of major flares is currently under study.

Levels of anti-nRNP and antibodies of other specificities decreased with clinical improvement, in general with the concurrent institution of immunosuppressive therapy. Corticosteroids are known to suppress IgG synthesis in vivo. ${ }^{14}$ Declining levels of immunoglobulins can also be attributed to azathioprine, cyclophosphamide, and methotrexate. ${ }^{15}$ The decline in anti-nRNP concurrent with clinical recovery as observed in the only patient who was not treated suggests, however, that spontaneous decline in the level of autoantibodies is also associated with decrease in disease activity. Another mechanism resulting in lowering of antinuclear antibody levels is the formation of complexes with free autoantigen. Free RNNP $^{16}$ has been shown like free DNA ${ }^{17}$ to be released in the serum when prednisone therapy is initiated or increased. Declining levels of anti-nRNP were not associated with increase in the levels of circulating immune complexes (results not shown).

To investigate whether anti-nRNP is a specific guide for assessing disease activity we studied the relation between fluctuations in anti-nRNP levels and antibodies of other specificities. We chose another autoantibody (IgM RF) and an antibody to an unrelated antigen (tetanus toxoid). The finding of parallel fluctuations, even with respect to total IgG levels, points to polyclonal B lymphocyte activation during active disease. Patients with autoimmune disease like SLE and MCTD make a large amount of immunoglobulins, and a large proportion of these may be autoantibodies. ${ }^{11} 18$ Raised levels of antibodies against common viral antigens were recorded by several investigators in patients with SLE. ${ }^{19}{ }^{20}$ Phillips and Christian even observed a relation between clinical activity of disease and levels of antibodies against viruses. ${ }^{20}$ Several in vitro studies have also shown polyclonal B cell activation in patients with active SLE. ${ }^{21-23}$ Whether antinRNP antibodies, by abrogation of $T$ suppressor cell function, ${ }^{24}$ have a role in polyclonal $B$ cell activation is not clear. 
808 Houtman, Kallenberg, Limburg, van Leeuwen, van Rijswijk, The

In conclusion, longitudinal measurement of antinRNP antibodies is of clinical value in predicting and assessing disease activity in patients with these antibodies. Fluctuations in anti-nRNP are not specific markers, however, but are an expression of fluctuations in polyclonal B cell activity. Thus for clinical purposes total IgG levels may equally well be used. Nevertheless, further elucidation of the pathogenetic significance of anti-nRNP antibodies is warranted.

The authors wish to thank Minke Huitema for technical assistance. This study was supported by the 'Praeventiefonds' and the Netherlands League against Rheumatism.

\section{References}

1 Sharp G C. Irvin W A. Tan E M. Gould R G. Holman H R. Mixed connective tissue disease-an apparently distinct rheumatic disease syndrome associated with a specific antibody to an extractable nuclear antigen (ENA). Am J Med 1972: 52: $148-59$.

2 Reichlin M. Problems in differentiating SLE and mixed connective tissue disease. $N$ Engl J Med 1976: 18: 1194-5.

3 Gilliam J N, Prystowsky S D. Mixed connective tissue disease syndrome: the cutaneous manifestations of patients with high titer serum antibody to RNase sensitive extractable nuclear antigen (ENA). Arch Dermatol 1977; 113: 583-7.

4 Alarcon-Segovia D, Ruiz Arguelles A. Fishbein E. Antibody to nuclear ribonucleoprotein penetrates live human mononuclear cells through Fc-receptors. Nature 1978: 271: 67-9.

5 Izuno G T. Observations on the in vivo reaction of antinuclear antibodies with epidermal cells. Br J Dermatol 1978; 98: 391-8.

6 Lerner M R, Boyle J A. Mount S M. Wolin S L. Steitz J A. Are nRNPs involved in splicing? Nature 1980; 283: 220-4.

7 Lightfoot R W, Redecha P B. Levesanos N. Longitudinal studies of anti-DNA antibody levels in SLE. Scand J Rheumatol 1975; suppl 11: $52-8$.

8 Swaak A G J, Aarden L A. Statius van Eps L W, Feltkamp T E W. Anti-dsDNA and complement profiles as prognostic guides in systemic lupus erythematosus. Arthritis Rheum 1979: 22: 226-35.

9 Moore T L, Weiss T D, Neucks S H, Baldassare A R, Zuckner J. Extractable nuclear antigens. Semin Arthritis Rheum 1981; 10: $309-18$
10 Houtman P M. Kallenberg C G M. Limburg P C. Huitema M G. van Rijswijk M H. The T H. Quantitation of antibodies to nucleoribonucleoprotein (nRNP) by ELISA. Clin Exp Immunol 1985: 62: 696-7()4.

11 Maddison P J. Reichlin M. Quantitation of precipitating antibodies to certain soluble nuclear antigens in SLF. Arthritis Rheum 1977: 20: 819-24.

12 Becker T M. Lizzio F. F. Merchant B. Reeves J P. Steinberg A D. Increased multiclonal antibody-forming cell activity in the peripheral blood of patients with SLE. Int Arch Allergy Appl Immunol 1981: 66: 293-303.

13 Siegel S. Non parametric statistics for the behavioural sciences. New York: McGraw-Hill. 1956.

14 Butler W T. Rossen R D. Effects of corticosteroids on immunity in man. I. Decreased serum IgG concentration caused by 3 or 5 days of high doses methylprednisolone. J (lin Invest 1973; 52: 2629-40

15 Hurd E R. Immunosuppressive and anti-inflammatory properties of cyclophosphamide. azathioprine and methotrexate Arthritis Rheum 1973: 16: 84-7.

16 Fishbein E. Ramos-Niembro F. Alarcon-Segovia D. Free serum nucleoprotein in mixed connective tissue discase and other connective tissue diseases. J Rheumatol 1978: 5: 384-9.

17 Hughes G R V. Cohen A S. Lightfoot R W. The release of DNA into serum and svnovial fluid. Arthritis Rheum 1971: 14: 259-66.

18 Holman H R. Systemic lupus erythematosus-discase of an unusual immunological responsiveness?' Am J Med 1959: 27: 525-8.

19 Hurd E R. Dowdle W. Casey H. Virus antibody levels in $\mathbb{D}$ systemic lupus erythematosus. Arthritis Rheum 1972: 15: 267-74.

20) Phillips P E. Christian C L. Virus antibodies in systemic lup erythematosus and other connective tissue discases. $A$, Rheum Dis 1973: 32: 450-6.

21 Fauci A S. Immunoregulation in autoimmunity. J Allergy ( $/$ rn Immunol 1980: 66: 5-17.

22 Hoch S. Schur P H. Schwaber J. Frequency of anti-DNA antibody producing cells from rormals and patients with systemic lupus erythematosus. Clin Immunol Immunopathol 1983: 27: $28-37$.

23 Kallenberg C G M. Limburg P C. van Slochteren C. van der Woude $\mathrm{F} J$. The $\mathrm{T} \mathrm{H}$. B-cell activity in svstemic lupus erythematosus: depressed in vivo humoral response to primary antigen (hacmocyanin) and increased in vitro spontaneous immunoglobulin synthesis. Clin Exp Immunol 1983: 53: 371-83.

24 Alarcon-Segovia D. Ruiz-Arguelles A. Llorente L. Antibody penetration into living cells. II. Anti-ribonucleoprotein IgC penetrates into $T$ lymphocytes causing their deletion and the abrogation of suppressor function. J Immunol 1979; 122: $1855-62$. 